D Shukla, NV Rao and R Kim

Retina-Vitreous Service,

Aravind Eye Hospital and Postgraduate

Institute of Ophthalmology, 1 Anna Nagar,

Madurai 625 020,

Tamil Nadu, India

Correspondence: D Shukla,

Tel: + 91452 5356100;

Fax: + 914522530984 .

E-mail: daksh@aravind.org,

daksh66@rediffmail.com

Eye (2006) 20, 1330-1332. doi:10.1038/sj.eye.6702198;

published online 25 November 2005

Sir,

\section{Expanding role of local anaesthetia in vitreoretinal surgery}

We read with interest the paper by Costen et $a l^{1}$, regarding the expanding role of local anaesthesia (LA) in vitreoretinal (VR) surgery. The study involved 1003 patients undergoing VR surgery, of whom 920 (91.7\%) had LA. They concluded that 'careful patient selection, together with the use of sedation when necessary, should ensure that the routine use of LA for VR surgery continues to become more acceptable to patients and medical staff alike'. Two of us have visited the Southampton Eye Unit and were very impressed with their VR service, but nevertheless we have some reservations about the conclusions of this study.

Every patient was under the care of a single consultant anaesthetist who works full time in ophthalmology. No doubt his considerable experience is responsible for the excellence of the blocks. However, this arrangement is impractical in many other hospitals. Anaesthetist staff may need to maintain skills in all areas of anaesthesia, if for no other reason than to carry out their on-call duties competently. Also, with less-experienced anaesthetist staff there will inevitably be a greater recourse to GA. Presumably all the LA surgery took place during routine surgical sessions. In other units when this is not possible, it would again increase the likelihood that a GA will be preferred.

The authors comment that in-patient beds are increasingly under pressure and hence general anaesthetic services are often stretched'. There is an implication here that the move to LA is in part driven by necessity rather than choice, and this may well be a factor in other units moving toward an increase in LA rates.

We note that top-up anaesthesia by sub-tenon's injection was required in $5 \%$ of cases overall, and sedation was used in $20.2 \%$. In this unit we have tended to avoid sedation because of concerns that the patient may not always be alert enough to cooperate fully during surgery.

We are puzzled by the inclusion of patients undergoing retinopexy without vitrectomy (group 2 'retinopexies with or without vitrectomy') GA would not normally be considered for such patients. Their inclusion perhaps lessens the impact of the headline LA rate.

There is no doubt that many patients are better served with LA vitrectomies than GA, especially insulindependent diabetics and those in poor general health. However, we do not necessarily see it as desirable to strive for the high LA rate that is advocated in this study. After all, a GA offers a painless alternative to the LA block, and recovery these days is quick enough to make it perfectly feasible for day case surgery. ${ }^{2}$ The greater degree of relaxation in teaching juniors, the avoidance of needles in close proximity to the eye, and the ability to treat the fellow eye, are obvious additional advantages of a GA.

\section{References}

1 Costen MTJ, Newsom RS, Wainwright AC, Luff AJ, Canning $\mathrm{CR}$. Expanding role of local anaesthesia in vitreoretinal surgery. Eye 2005; 19: 755-761.

2 Lagasse RS. Anaesthesia safety: model or myth? A review of the published literature and analysis of current original data. Anesthesiology 2002; 97(6): 1609-1617.

R Gray', J Lucas ${ }^{1}$ and R Sidebottom ${ }^{2}$

${ }^{1}$ Taunton and Somerset Hospital, Musgrove Park, Taunton, Somerset TA1 5DA, UK

${ }^{2} \mathrm{SHO}$ Ophthalmology, Taunton and Somerset Hospital, Musgrove Park, Taunton, UK

Correspondence: R Gray,

Tel: +44 1823333 444;

Fax: + 441823342943 .

E-mail: roger.gray@tst.nhs.uk

Eye (2006) 20, 1322. doi:10.1038/sj.eye.6702199; published online 2 December 2005

Sir,

\section{Reply to Gray et al}

We note with interest the comments made in the letter from Gray et al, and thank the authors for their interest in our paper. 